This item was submitted to Loughborough's Research Repository by the author.

Items in Figshare are protected by copyright, with all rights reserved, unless otherwise indicated.

\title{
The Scottish credit and qualifications framework: what's academic practice got to do with it?
}

\section{PLEASE CITE THE PUBLISHED VERSION}

http://dx.doi.org/10.1111/ejed.12056

\section{PUBLISHER}

(C) John Wiley \& Sons Ltd

\section{VERSION}

AM (Accepted Manuscript)

\section{PUBLISHER STATEMENT}

This work is made available according to the conditions of the Creative Commons Attribution-NonCommercialNoDerivatives 4.0 International (CC BY-NC-ND 4.0) licence. Full details of this licence are available at: https://creativecommons.org/licenses/by-nc-nd/4.0/

\section{LICENCE}

CC BY-NC-ND 4.0

\section{REPOSITORY RECORD}

Fernie, Scott, Nick Pilcher, and Karen L. Smith. 2019. "The Scottish Credit and Qualifications Framework: What's Academic Practice Got to Do with It?”. figshare. https://hdl.handle.net/2134/17694. 
The Scottish Credit and Qualifications Framework: what's academic practice got to do with it?

Fernie, S. Heriot Watt University

Pilcher, N. Edinburgh Napier University

Smith, K. University of Greenwich

Corresponding author: Scott Fernie, School of the Built Environment, Heriot Watt University, Edinburgh, Scotland, EH14 4AS. Email: $\underline{\text { S.Fernie@hw.ac.uk }}$

\begin{abstract}
National Qualifications Frameworks (NQF) are a globally established and expanding phenomenon. They are increasingly merging and being mapped onto meta-qualifications frameworks. One key NQF in both these roles is the Scottish Credit and Qualifications Framework (SCQF). There is much research that categorises the different types of NQF, details their success and failure, and there is a steadily expanding body of critical research into NQF. Despite this, little research has focused on how NQF are used in day to day academic practice in the very institutions whose qualifications they frame. This paper begins to redress this through focusing on the SCQF as an exemplar. It presents a synthesis between contemporary literature, documentary analysis of SCQF literature and the data from in-depth interviews with 15 stakeholders from a range of educational roles. The findings show that despite the claims of the SCQF literature and of contemporary literature regarding the success of the SCQF, its diffusion and the extent of its use amongst these stakeholders is limited. Instead, it is used more as a symbolic tick box exercise and largely ignored. We discuss the implications of this and posit a number of questions that challenge the focus of existing research into NQF and argue for a shift in the criteria by which they are judged from educational to market based ones.
\end{abstract}




\section{Key words: National Qualifications Frameworks; Dissemination; Higher Education; academic practice}

\section{Introduction}

Qualifications frameworks have been developed and used with increasing frequency around the world. Within Europe, there even exists a 'meta' framework, the European Qualification Framework (EQF) that attempts to harmonise and consolidate multiple national frameworks into a single point of reference (cf EUA 2005; Bologna 2007; EUA 2010; UK EQF 2010; Karseth \& Solbrekke 2010). One of the first national qualification frameworks to be mapped on to the EQF was the Scottish Credit and Qualifications Framework (SCQF). Notably, the SCQF is one of the more mature qualification frameworks in Europe and is, ostensibly, one of the early 'success stories' (Young 2003). It is for this reason that the research in this paper focuses on the SCQF as it offers opportunities to contribute to growing debates concerning NQF within the field of education policy research (c.f.Allais 2007a; 2007b; Young 2008).

Whilst previous accounts of the SCQF have engaged with policy stakeholder groups (cf Raffe 2003; Gallacher et al. 2005), an altogether different set of stakeholders interpretations were explored in this research to provide deeper insights regarding the impact and diffusion (success) of the SCQF and more widely, NQF. Consequently, the research provides a novel account of how the SCQF is perceived and used (or not) by higher education practitioners who are argued to be instrumental in its application, fundamental to its diffusion and the beneficiaries of its use (c.f. SCQF 2009). It is argued here that the aims and goals of the SCQF are inextricably connected to academic practice. The research reported here explores this connection and impact. The overriding research aim is to develop insights into the diffusion, and impact of the SCQF on academic practice in higher education. 
The paper is structured in five parts. The first part critically explores current thinking, arguments, debates and research perspectives on NQF, the EQF, the SCQF, and academic practice. Furthermore the relationship between the SCQF and academic practice is discussed in order to underpin the research aim. The second part describes the methodological approach underpinning the research and the methods of data collection and analysis. The third presents an overview of the SCQF drawing on the 2009 user guide and handbook (SCQF 2009), to identify aims, objectives, stakeholders, and intended impact of the framework, with a view to reinforcing the connection between the SCQF and academic practice.. Part four draws on the findings from the interviews and synthesises these with the critical exploration in part one and the overview in part three. A final part forms conclusions through a discussion.

\section{Types of National Qualification Frameworks}

It would be quite misleading to assume that education policy makers across nations draw upon a singular perspective regarding the form, purpose and process of implementation of qualification frameworks. Broadly, frameworks can be viewed as being either 'Outcomes-led framework[s]' or 'Framework[s] of communication' also known as ‘Organization Frameworks' (see Allais 2007a; Allais and Young 2009). 'Outcomes-led frameworks' and 'Organization Frameworks’ have significant similarities. Both aim to make qualifications transparent to all users of the framework. Such transparency, it is argued, will facilitate: the movement of students and workers; the massification of higher education; lifelong learning, direct entry and widening of participation in higher education (e.g. Gallacher et al 2005; EUA 2010). What sets these different types of framework apart is their respective assumptions regarding the degree of transformation - if any. 
Outcomes-led frameworks aim to transform and provide increased quality by instrumentally using an NQF to guide transformation, for example, the NQF in South Africa (Allais 2009). In contrast, Framework[s] of communication and Organization Frameworks (such as the SCQF) are argued to be concerned with developing a reference point to map and connect the development and delivery of current and future qualifications. It is the development and delivery of these qualifications that places academic practice at the centre of any framework. The organisation framework explicitly ‘bolts onto’ existing quality assurance mechanisms and cannot be disconnected from the central role that academic practice plays in the delivery and quality of educational qualifications. Clearly, both types of framework present very different challenges with respect to innovation-diffusion (Fernie and Pilcher 2009), scope for impact and underlying rationale.

Recognising this disparity, a growing, but limited, number of critiques are beginning to explore the rationale(s) of NQF (Blackmur 2004; Young 2008; Fernie and Pilcher 2009; Blackmur 2010). Research that engages with and explores the disparate range of interested and affected stakeholder's interpretations has much to offer outcomes-led or organisation-led forms of qualification frameworks. For example, it may be useful to understand whether all stakeholders concur on the aims and goals of any particular NQF and see its relevance to academic practice, or indeed, whether there is agreement on the framework being outcome or organisation-led. Furthermore, is there a gap between aims and objectives of NQF and substantive academic practice - in other words, is there substance or just symbolism to the diffusion of NQF. Furthermore, are stakeholders aware of and actually understand their respective NQF, its role and relationship to their academic practice and, do stakeholders in some cases even need such knowledge? To some extent, stakeholder engagement and understanding of NQF has been investigated and concerns have been raised with regard to the 
lack of stakeholder knowledge (Gallacher et al. 2005; Raffe 2009a; EUA 2010). Few of these have explored the relationship between NQF and academic practice. Exploring this relationship is of course predicated by an assumption that there is an intended relationship between academic practice and NQF (in this case the SCQF). The underpinning assumption of the research presented here is that there is a relationship between NQF (specifically the SCQF) and academic practice and we elaborate on this assumption here with a brief definition of academic practice and illustration of its resonance within the SCQF handbook and user guide.

Academic practice is argued to cover a wide range of activities such as: curriculum development, design and delivery; supervision and student support; scholarship, research and enterprise; recruitment and admissions; responding to strategic initiatives and committee work; ; and managing research and academic departments (Brew, 2010; Fry et al. 2009; McAlpine et al 2011; Warwick 2011). Similarly, the SCQF is broadly argued to be "used by all those with the responsiobility for the development and delivery of qualifications and learning programmes” (SCQF 2009:11). To guide those with such responsibility the SCQF seeks to influence the way in which education is described, designed and delivered. For example, the SCQF is argued to be instrumental in determining exit and entry points and as such cannot be divorced from academic practices associated with admissions. Furthermore, learning is described and designed through the use of learning outcomes, notional learning hours, methods of assessment and an appropriate quality assurance system. Indeed, to be clear, the SQF forms one of four components of QAA within Scottish HEIs, the others being subject benchmark statements, codes of practice and programme specifications (QAA 2011a). Furthermore, the QAA also states that, "the threshold academic standard of all higher education awards is at least consistent with those set out in a named higher education 
qualifications framework” (QAA 2011b: 22). In essence the SCQF provides a template on which most pre-existing learning programmes could arguably be structured. However, such a template also provides constraints upon future design and delivery of learning programmes. When such programmes are designed, it is inevitable that consideration is given to how they are taught, what is learnt, how research is done, and also how such programmes are managed and delivered. As such, any consideration of a qualification with regard to how it fits into the framework must inevitably involve structuring or redesigning academic practice across a broad range of activities.

The key proposition explored in the case study is that the SCQF should be having an impact on academic practice given what is said about it in the more general literature and documentation discussed above, and in the more specific documentation discussed below.

\section{The Scottish Credit and Qualifications Framework (SCQF)}

As a frequently cited example of a successful NQF (c.f. Allais 2007b; Young 2008; Raffe 2009a; SCQF 2010a), the SCQF, even as far back as eight years ago, was argued to be " $a$ qualifications system that is already much more unified than in most other countries" (Raffe 2003: 242). Similarly, in 2005 the SCQF was considered to be an exemplary framework; "in Scotland the Scottish Credit and Qualifications Framework (SCQF) is a detailed agreement between stakeholders that entails no legislation" (Bologna 2005:33). It therefore presents an excellent opportunity to engage with multiple stakeholder interpretations of a mature and arguably well established and embedded NQF. 
As the SCQF “has not aimed to challenge existing educational or social hierarchies” (Raffe 2003: 252) and, is argued to be concerned with providing "rationalization, not creation" (Gunning 1999, p.5), it would appear to be an organisation-led framework. Furthermore, the Framework also has “no regulatory framework” (Raffe 2007:485) and its adoption is therefore voluntary. The perceived success of the SCQF and its implementation would also appear to support a view that transformation has been minimal and thus its diffusion largely unproblematic. In other words, that it has not affected (or transformed) the content (and related delivery) of modules, and, as a result, has faced few obstacles (or problems) in being communicated and used (diffused). Furthermore, a recent SCQF Partnership commissioned report notes the SCQF “has been reasonably well communicated in mainstream education” (SCQF 2010a:4). Although it is possible to argue that the wording 'reasonably well communicated' allows for a number of caveats, it is safe to assume that its intended meaning is similar to 'a large number of people know a reasonable amount about its aims and content'.

However, any attempt to rationalise will indirectly have transformative properties. For example, mapping qualifications onto a rationalized system may require the transformation of that qualification. Such mapping also implies that all stakeholders are knowledgeable of the system. Yet, one study of the SCQF found possession of such knowledge across stakeholders to be inconsistent (Gallacher et al. 2005). In addition, contrary to the aim to provide transparency to a wide range of stakeholders, the study found that the SCQF resonated more with educational institutions than with employers. The study also found that practitioners using the SCQF expressed significant concern that "the Framework had encouraged unrealistic expectations regarding the potential for the framework to introduce change" (Gallacher et al. 2005: no page). The intended scope and function of the SCQF, is therefore potentially at odds with the way it has been interpreted during the process of diffusion. It is 
particularly notable that in Gallacher et al's. (2005) evaluation of the SCQF it was clearly assumed by interviewees that transformation and change are central to the SCQF. Of course, such views are very much dependent on who the stakeholders are and which group of stakeholders form the basis of any such research and evaluations. There appears to be mixed views regarding the nature of transformation with respect to the SCQF and its impact upon disparate stakeholder groups.

Bologna notes the importance of stakeholders in higher education and gives a list of these important stakeholders as follows:

"stakeholders may include: learners/students; providers of education and training; government and appropriate government agencies; awarding bodies; higher education professors/teachers; employers and the business sector; trade unions; community and voluntary organisations; professional bodies; etc.” (Bologna 2005: 53).

Whilst the dominant literature looks at a range of stakeholders, it is often less clear as to who these are (e.g Raffe 2009a). A critical perspective that engages with higher education stakeholders is largely missing in contemporary literature that reviews or critiques the SCQF. Such research may provide answers to Raffe's (2007) concern that the "Full use of the Framework" has not yet been achieved. It is especially important and necessary for such reviews and critiques to be explored from a number of perspectives. For example, SCQF (2010a) provides views from different stakeholders with respect to the successful impact of the SCQF partnership, executive team, forum and framework. However, the emphasis of such research is on the SCQF rather than on the actual practice of the stakeholders such as higher education practitioners (cf Raffe 2009a). In other words, it does not critically investigate how 
much and to what extent the SCQF has changed (or not changed) people's practices, rather it simply asks to what extent the SCQF has been successfully implemented. Whilst such research makes a notable contribution, it does not draw into the debate and discussion issues surrounding innovation diffusion, organisation practice, education pedagogy or resistance to change. These issues are arguably crucial lines of argument and debate to be pursued if we are to fully comprehend the impact of the SCQF on practice and a wider view of its success. Moreover, such issues need to be addressed if we are to fully understand to what extent the SCQF is able to affect the quality of higher education practice. For example, does it: clarify entry and exit points, and routes for progression (SCQF 2001); impact upon programme and course design and; provide a source of reference for quality in higher education? These represent a list of concerns and issues that would be at the heart of higher education interpretations of the impact of SCQF previously unexplored.

Clearly, there is significant scope to further explore and provide insights into the diffusion of the SCQF and for such research to provide wider insights into the development and diffusion of NQF elsewhere (cf Ireland (HETAC 2007); Poland (IBE 2010)). Drawing on the above arguments, the research presented here assumed that the SCQF is intended to impact upon academic practice (the creation, delivery, description and assessment of academic courses of study), that all higher education stakeholders are aware of and understand the SCQF (albeit possibly differently) and that the rhetoric contained in the SCQF guidance documentation regarding aims, objectives and rationale would have been widely understood and successfully implemented. If this assumption proved to be false, then both the claims, and more notably, the purpose, of the SCQF would be very different from those made in the handbook (SCQF 2009). 


\section{Research approach}

For this research, a single case study approach was chosen. The single case chosen was the SCQF, and the unit of analysis (Flyvbjerg 2011) were the interpretations and diffusion of the SCQF. The context for the study was a pre-1992 Scottish university chosen principally for 'ease of access and 'agreement' to participate (Bresnen 1988). The single case study research strategy was therefore used to explore and explain a particular phenomenon of interest in a specific context. The case study approach (Eisenhardt 1989, Stoecker 1991, Flyvbjerg 2011) was considered appropriate given the research study sought answers to 'how' type questions in social situations where the researchers had little control over the contemporary phenomena of interest. . As will be explored in later sections, the research strategy was based on key theoretical propositions categorized by themes. This formed the basis of a template with which to iterate between the extant literature and interview data from stakeholders within the context of study. The results are intended to provide 'concrete case knowledge' (Flyvbjerg 2011).

\section{Scope of Research}

The context for this research was a pre-1992 higher education institution in Scotland.

Although it is not possible to reference any documents from the institution studied for reasons of anonymity, significant documentation exists that both guides and frames a number of key academic practices using the SCQF: ongoing evaluation, approval and description of programmes of study, and assurance of academic standards. Indeed, in the approval for new programmes there is an 'explicit statement of compliance' that SCQF levels are adhered to. 
These documents are also intrinsically connected and designed to meet the needs of the broader QAA requirements described previously with respect to the role of the SCQF. Any person reading such documents could not fail to assume that the SCQF was widely influential on academic practice and, as we show below, was, according to SCQF documentation, widely used and known by those in the institution. Furthermore, the university runs a Higher Education Academy (a UK organization which supports learning and teaching within higher education and runs a professional recognition scheme for staff) accredited Postgraduate Certificate in Academic Practice, which uses the SCQF as a pivotal reference point for alignment and codification of learning and teaching activities, intended learning outcomes and assessment methods. It cannot be argued therefore that the SCQF is not designed to impact upon academic practice.

The institution has a number of students from Scotland, the EU, and other countries from around the world, and is a relatively large institution. As such, it is representative of higher education institutions which use the SCQF. The institution has adopted the SCQF and uses the SCQF significantly within its documentation concerning education delivery and quality assurance. Its existence and use in documentation is not however accepted here as evidence of its implementation and impact upon the practice of higher education practitioners. Indeed, such rhetoric is useful as a reference point for exploring higher education practice.

\section{Documentary analysis}

Further documentary data comprised the SCQF user guidelines document from 2009 (SCQF 2009). As Prior (2003) notes, any document is 'packed tight with assumptions and concepts and ideas that reflect on the agents, and its intended recipients, as much as upon the people and events reported there' (Prior 2003; 48). Consequently, we used the documentary analysis 
to generate key concepts and ideas (themes) which would be mutually understood by members of the professional or academic community in which they regularly occur, in our case learners, lecturers, admissions tutors, strategic managers, and program leaders in the case study. In order to assess how these key themes are understood and enacted, other data collection methods were used. The second major source of data was the interviewing of 15 practitioners within the case study organisation.

\section{Interviews}

In-depth interviews were conducted with 15 stakeholders who fell into one or more of the following categories: learner (3); lecturer (8) ; course and programme administrator (4); recruitment and admissions (5); and strategic management (4). Ethical approval was gained for the project prior to its commencement. . Interviewees were assured every effort would be made to ensure no connection between themselves and the data (Sikes 2010). Interviews ranged from 20 to 90 minutes and yielded 118,606 words of raw data. In order to shift the balance of power in the interview (Foucault 1973) more towards the interviewee, spider diagrams rather than questions were used to give interviewees more choice over the direction of the interview and to make the interview more of a discussion rather than pure question and answer. Interviewees were asked reflexive questions at the end (Jia 2001) to explore their opinions on whether any areas had been left uncovered. The interviews were transcribed by the researchers using a self-designed transcription approach (Poland 2001) and sent to the interviewees for approval. For analysis interviews were coded by the three researchers individually using Nvivo8, and then second coded for verification. These codes were then merged into four key themes of rationale/aims, extent, intended audience, and mapping to facilitate further iteration between the extant literature, the 2009 SCQF handbook and the interview data. 


\section{Findings}

The findings are drawn from the documentary analysis and the interview data. First, an overview of the SCQF (based on the 2009 SCQF handbook: user guide) is presented. Following this, more specific findings which relate to the key themes (propositions) are presented from both the 2009 SCQF handbook and the interview data.

\section{An overview of the SCQF}

The SCQF is the acronym for the Scottish Credit and Qualifications Framework. The impetus for the SCQF came from the Dearing report (National Committee of Inquiry into Higher Education \& Dearing 1997) which recommended that Scotland establish its own framework for credit and qualifications that was separate from an English one, due to the distinct nature of the Scottish education system. This was developed by drawing upon the previous work on credits (see Menmuir 2003), qualification frameworks (see SCQF 2011) and the work of the Scottish Qualifications Authority (SQA). The SCQF handbook: user guide (SCQF 2009), although not significantly different from earlier versions, “supersedes all previous versions” (SCQF 2009:5). The handbook notes the SCQF was launched in 2001 and is now run by the SCQF Partnership. Within the UK's legitimised system of quality assurance, “the SCQF is a voluntary Framework” (SCQF

2009:11) for higher education institutions to adopt and implement. Coupled with the 'Code of Practice'; 'Programme Specifications'; and 'Subject benchmark statements', the SCQF contributes to this robust quality assurance system for academic infrastructure. Management of quality is undertaken by 'The Code of Practice' "and the other three give advice to institutions about setting standards” (QAA 2011). The SCQF is, therefore, highly influential in the delivery of higher education practice and plays a key role in legitimising quality. In order to do this it has both external ('outwardly focused') and internal ('inwardly focused') 
roles. This forms the basis of one of the propositions of the research; the SCQF should impact upon and influence academic practice.

The external, 'outwardly focused' management role is exercised through a “European and International Group” (SCQF 2009:14) and is connected to the Bologna process, in that

"One of the key features of the Bologna process is the development of national qualifications frameworks in each country and the development of criteria and procedures to be used by each country to verify that its national framework is compatible with an overarching Qualifications Framework for the EHEA” (SCQF 2009:90).

The internal role is inextricably linked to the Quality Assurance Agency for Higher Education Scotland and the Scottish Advisory Committee on Credit and Access (SACCA). The SCQF partnership board, along with the Executive team, receives advice from the SCQF Forum, to "ensure that the Framework continues to meet the needs of all learners, employers and other users of Scottish learning provision” (SCQF 2009:14). This means that all learning that occurs takes place “within an appropriate quality assurance system” (SCQF 2009:42), and, importantly, “The SCQF should be used by all those with responsibility for the development and delivery of qualifications and learning programmes, in order to meet local and national education and training needs in Scotland” (SCQF 2009:11). The framework is therefore fundamental to all stakeholders within higher education and undoubtedly intervenes in the process of course and programme design, a key element of academic practice. The research proposes thus that all stakeholders within higher education are familiar with and use the SCQF. 
The following sections explore key themes that emerged. The themes are central to the discussion generated in the paper and pivotal to answering the research aim: to explore the diffusion of, and impact of the SCQF on practice in higher education.

\section{Rationale / Aims}

There is a significant emphasis within SCQF on what has rapidly become 'de rigueur' in education policy and discourse within Scotland and across Europe: widening participation and opportunities for lifelong learning (c.f. Green 2002, EC 2005, SFC 2005, OECD 2007, Mullen 2007, 2010, Raffe, 2008, 2009b). Coupled with this, are a number of clear and simple associated 'learning' aims that are undoubtedly related to higher education management and education practice:

- "Make the relationships between qualifications and learning programmes clear;

- Clarify entry and exit points, and routes for progression;

- Maximise the opportunities for credit transfer;

- Assist learners to plan their progress and learning;

- Minimise the duplication of learning” (SCQF 2009:11).

Central to this clarity and simplicity is the shift from a qualification system that emphasises 'how’ qualifications are achieved as a significant determinant of the outcome (qualification) to a framework-led approach where, qualifications are mapped according to specific generic outcomes (learning) largely disconnected from any singular perspective regarding how such learning is achieved (Young 2008). In essence, the framework approach assumes how learning 'occurs' to be pluralistic and as such, scope, time, place, processes and mechanisms 
associated with how individuals learn are widened and recognised by, and through, the framework. In doing so, duplication of learning is minimised and credit transfer maximised by this pluralist approach to the context and scope for learning. Arguably higher education institutions provide only one context and pedagogic approach to how learning can be achieved.

Coupled with this pluralism is, paradoxically, a singular set of learning outcomes, albeit categorised as 'generic' and as such open to significant interpretation within one stakeholder group let alone multiple stakeholder groups. Such pluralism though, in how learning occurs, is not entirely without constraints in the form of 'credits' measured by 'notional' periods of study time and levels to separate hierarchically, future and currently available qualifications and years of study. Practices associated with these constraints are what Dixon (2009) refers to as curricular accounting leading to further propositions that complying with frameworks becomes a bureaucratic ‘tick box’ exercise (see also Young 2008). Despite such criticisms, the Framework is thus argued to provide the basis for clarifying exit and entry points for those responsible for admission to programmes of learning within learning providers.

The Framework is also considered to facilitate the ability of learners to plan their progression from one level of the framework to another without necessarily having recourse to fully commit themselves to a prescribed timeframe, place and institution within which to learn and progress. The Framework also provides one of the most influential guiding documents for the ongoing design and delivery of programmes and courses within all Scottish higher education bodies seeking institutional accreditation from QAA. 
Notably however, real depth of understanding concerned with aims of the SCQF such as widening participation, lifelong learning, learning outcomes, pluralistic learning mechanisms and contexts, were largely absent from interviewee interpretations (cf Bologna 2010). Direct reference to these aims was rare amongst those stakeholders actively engaged in academic educational practices. Furthermore, meaningful detail on 'how' the framework facilitated these aims was largely absent. In the main, excluding those in centrally located strategic management positions in the University, the lecturers, students and course leaders interviewed typically gave accounts of the SCQF based on minimal use and limited knowledge. For example, one admission tutor stated that "I think most people haven't a clue what it is" and an experienced lecturer stated that "I'm not at all familiar with the content of the SCQF”. Notably, as the previous quote demonstrates, most had never read the content of the SCQF documentation. Moreover, various stakeholders, including an admissions tutor and two students had also never even heard of the SCQF before being interviewed. Essentially, there was no connection between admissions practices in higher education and the aim of the SCQF to clarify entry and exit points.

Despite the above, strategic management interpretations of the SCQF demonstrated a deeper grasp of the aims and rationale of the SCQF. One account stated that the SCQF aimed to "provide a natural framework to establish these equivalences to encourage mobility between these different types of educational institutions and therefore educational experiences”. Similarly, another account stated that "the aims are about widening participation making bridges and ladders as they say and making sure that there's mobility within the UK and between countries”. Furthermore, when asked if the SCQF had improved the performance of universities, the aim of transparency loomed large in one interpretation - “it’s a good question I think it's improved a transparency of what we offer". There is undoubtedly vague 
recognition of the aims to broadly clarify entry points, exit points and progression routes through this language of mobility, widening participation and transparency.

These strategic management views must be counterbalanced with others that interpret the SCQF as having no shaping influence on academic practice. Rather, engagement with the SCQF is viewed as a matter of post-rationalisation to ensure 'fit' - "the end point is defined by us as an institution and we check that it fits the SCQF". This view is complemented by the strategic management view “that the framework doesn't determine who comes in, by and large didn't work that way". This contradicts the aim of the framework to clarify entry and exit points. Intriguingly, strategic management interpretations went beyond the stated aims of the SCQF to include wider political and commercial interests:

"there was a political agenda there I think to try and also use the framework to expand internationally and I mentioned China where you know it's been very successful with the SQA and in developing those programmes internationally and not just in China, it's a big international operation longer term I think again if you'd say the international agenda there is I think a definite agenda for potentially recasting the way that FE and HE interact with each other and of course you know I'm taking about the upper end of the framework".

There is very limited documentary evidence with which to compare and contrast this emergent interpretation regarding politics, but there is certainly more empirical evidence of the interaction between $\mathrm{HE}$ and FE discussed in the following key themes. Neither, however, forms any explicit aim in the SCQF documentation.

\section{Extent}


The user guide notes the SCQF is well established: "since its launch in 2001, the SCQF has become well established as the means to describe Scottish qualifications and learning programmes in terms of their level and credit (size)” (SCQF 2009:1). This has been done through availing stakeholders of "appropriate sources of information, advice and guidance” (SCQF 2009:43). Through such sources, stakeholders can “assist learners to plan their progress and learning” (SCQF 2009:11). The interview data showed however that most learners had little or no idea of its existence, although one learner noted they knew level 10 was degree level as they had seen it on official course documentation.

Another lecturer felt, in their role as admissions tutor, that “lecturers probably know most about it because they interact with it most directly," although, this was not echoed by other lecturers. Despite the User Guide noting that all those who used the framework would help “maintain the consistency and quality assurance of the framework" (SCQF 2009:12) one lecturer felt it was far above them: “I don't think it trickles down to the likes of me in terms of how is SCQF performing”. Similarly, another lecturer (and programme leader) thought most lecturers would devote very little time to the SCQF: “in all honesty I think the vast majority of them [other academics] don't think about it” whilst another believed it had very little relevance to the majority of the stakeholders: "I'd be surprised if anything close to $20 \%$ of the people within those different groups [learner; lecturer; course and programme administrator; recruitment and admissions; and strategic management] have ever actually looked at the framework or have any great knowledge of its content”. Reinforcing this view another lecturer (and admissions tutor) echoed this, and confirmed the minimal effect the SCQF had “actually, the long and short of it is that I don't think it really has any bearing, or perceived to have any bearing on, what I do". For one course director and lecturer the SCQF is discussed during periods of restructuring “I think it's peaks and troughs. I think it becomes 
a priority at events like reaccreditation or restructuring...but on a day to day basis...I don't think they form part of my activity as a course director or lecturer really”. In addition one strategic management stakeholder feared that it may be simply an empty shell: "I think the danger is that it just becomes you know a rather empty shell where you are simply mapping on years of study in a similar way as you say HND is two years of study so it's equivalent to post second-year university well er that's a statement in itself so that cannot be realised you know that's the issue."

There is thus a considerable disparity between these stakeholders understandings of the extent of impact on practice in higher education by the SCQF and claims by the SCQF itself that it is established. It is perhaps telling that impact on academic practice was low considering that one member of strategic management felt that lecturers had no need to know about the framework as such knowledge was considered to be part of the organisation's “institutional memory”. This manager argued that the SCQF already mirrored academic practice: "remember, people on the ground don't know about the framework, they don't need to know about benchmark statements, they don't need to know any of this stuff. That's just good practice as far as they are concerned”. The SCQF is in the main not considered to be an intervention, a guide or reference point for quality but simply reflective of current practice. However, if the SCQF is not considered to be relevant to academic lecturers in the design and delivery of ongoing learning material then who are the intended beneficiaries of the SCQF?

\section{Perceived intended beneficiaries}

The SCQF documentation highlights a significant list of stakeholders either involved in its application or potential beneficiaries such as "employers, learners and the public in general.........the skills of the workforce” (SCQF 2009:1) Another unspecified group of 
stakeholders are argued to have been and will continue to be consulted to "capture fully the experiences of the many people within a wide range of organisations that use the SCQF" (SCQF 2009:1). Furthermore, a further group of stakeholders are also used in the guidelines and comprise; Scotland's Colleges, Higher Education Institutes, the SQA and 'other' organisations approved by the SCQF Partnership. There is notably little reference directly to academics per se although much of the content of the SCQF and its use as part of QAA implies impact on academics and their practice.

When discussing the SCQF and the intended beneficiaries, interviewees, whilst in the main drawing on a limited grasp of the SCQF, provided a varied and illuminating set of views and opinions. These varied from "it's for everybody" to "it's different things for different people" to one strategic view that the SCQF is not for those who actively deliver educational opportunities.

Firstly, for lecturers, there were little or no interpretations that supported a view that the SCQF was beneficial to lecturers during the design and delivery of programmes or courses. Whilst most were aware of the term SCQF and others knew of the need to have the relevant SCQF level on their course material, few discussed it as pivotal to any substantive design and delivery of courses. However, a number of interviewees did seem to associate the SCQF with quality. For example, one student noted that "certainly these days if people are paying for their education ... it should be of a certain standard”. In this sense the SCQF should certainly be making an impact upon academic practices.

Secondly, its active use by admission tutors in the schools is largely absent and offers no benefits in this respect. Whilst one tutor was unaware of the Framework, another defaulted 
predominantly to frameworks used by professional bodies rather than the SCQF. Indeed, the SCQF is rather silent on the concern of programme leaders that programmes of study need to be professionally accredited. Potential conflicts between frameworks, and which takes precedence, is not discussed in the SCQF but, from the interpretations provided in this data, preference is given to professional frameworks on the basis that these are more pressing, well established and relevant to professionally accredited qualifications.

Furthermore, the argument that the SCQF “can assist advanced entry into other programmes” (SCQF 2009:53) is counterbalanced by the autonomous power of admission tutors to selectively ignore the SCQF when it suits. Notably, it should not be assumed that "SCQF credit points can be automatically accepted for entry or transfer to another qualification or learning programme" (SCQF 2009:53). As one strategic view noted - "when the SCQF came in, the colleges I think felt empowered if you like to be knocking on the university doors”. Nevertheless, higher education strategic views and those of central admissions were ones that remained very sensitive to managing this perceived aspiration and challenge to the autonomous power of universities to define entry and exit points for themselves.

Lastly, the question surrounding who are the intended beneficiaries went beyond simplistic interpretations relating to internal stakeholders. One view saw the Scottish Government benefiting from the SCQF as they "love it; it's a way of making very very complex things, makes it too simple in fact”. Furthermore, another strategic management view added that "tension is always likely to be there between autonomy and accountability for public funding”. Clearly, the data collected in this study indicates that the SCQF (and, arguably 
other NQF) forms part of a bigger political, economic and social debate and exploring the politics of the SCQF is outside the scope of this study.

Despite all of the above, perhaps the most poignant of views regarding beneficiaries of the SCQF came in the words of the following interviewee - "I'm not convinced that it's really filtering through”. Beyond symbolism and what Young (2008) described as a bureaucratic 'tick box' exercise, it proved particularly problematic to challenge this view with respect to substantive diffusion of the SCQF.

\section{Mapping}

Mapping, according to the interviewees, was to provide a means of comparison across education. It was seen as a mechanism for allowing cross comparisons to be made between contexts, in the words of one strategic manager thereby enabling people "to compare the cost of a pack of digestives and a pack of hob nobs”. In this way, the SCQF was seen as a 'common unit' or 'currency', allowing students to present, in a uniform way, their transferrable achievements, helping aid mobility (cf Bologna 2010). This focus on comparison is also present in the SCQF documentation: "the SCQF provides a means to compare and relate qualifications” (SCQF 2009:13) and “SCQF Credit Points give learners, employers and learning providers a means of describing and comparing the amount of learning that has been achieved” (SCQF 2009:35). In general, the interviewees described such mapping as 'laudable’. There did, however, appear to be a belief that while a comparison framework was good in theory, the SCQF did not work or had limited impact on practice. In other words, courses did not map on as easily as an organization framework would suggest they should. 
For academics, the SCQF is "only a bit of bother when you have to change module codes" and in this sense had become a 'rather empty shell'. Furthermore, one lecturer recounted how they had wanted to map an ab initio language module to level 5 but "when I presented I was told no you can't use level 5” and that it had to be mapped at SCQF level 7, despite the fact that the students had no prior knowledge of the language. This goes beyond bureaucratic tick boxing (Young 2008) and demonstrates a potential challenge for academic practice and practitioner's judgement.

Nevertheless, some of the interviewees associated mapping with equivalence. The SCQF was seen as a tool to help them see equivalence between credits, courses, modules, or countries. One strategic manager noting, "the bits that we are interested in are to do with comparability of degrees in other institutions and particularly across Europe and that links to the use of Bologna”. The SCQF documentation, however, is very clear in its view of this: "it is also important to note that the SCQF does not demonstrate equivalence or interchangeability of qualifications” (SCQF 2009:12). While expecting some equivalence, the interviewees broadly viewed the SCQF as having very little to do with process of delivering education or pedagogy and with the subject matter taught.

Mobility also seemed central to some interviewees understanding of mapping. One view considered that the SCQF could provide students with greater freedom and choice of study location; “I think it's a good thing like Bologna process, it certainly makes things easier for students to come across to different countries”. The interviews in this study, however, showed very little awareness or concern around the relationship between the SCQF, the EQF and Bologna.

The broad aims of the SCQF of clarity, comparison and mobility were identified both within the SCQF documentation and through the discussions with the interviewees. It does appear, 
however, that the interviewees expect much more from the SCQF than it actually delivers: equivalence, clear transfer pathways within and outside of Scotland, connected qualifications frameworks and explicit quality checks to legitimise programmes. Instead this Framework is interpreted extremely flexibly and appears to have a very limited impact on education.

\section{Discussion}

Contrary to the aspirations of the SCQF (e.g. SCQF 2009; SCQF 2010b), it is difficult to argue, as a consequence of this study, that the SCQF has made any significant progress on some of its key aims and consequently on the academic practices of many of its stakeholders. There is little evidence to suggest the Framework is used as an instrumental benchmark to aid in the design and development of programmes and courses. Its practical use is generally symbolic and takes the form of ticking boxes and labelling course documentation. It is therefore questionable if the aims to minimise duplication of learning, to define entry and exit points, and the maximisation of credit transfer (SCQF 2001; 2009; 2010) have been achieved. . Indeed, it would appear that there is a substantial gap between the rhetoric, aims and objectives of the SCQF, and the reality of its effect on learning, pedagogy or academic practice. Notably, it is necessary to provide a caveat here that many talked about the SCQF in abstract terms as most had very little knowledge of its content and detail. This in itself was quite a telling piece of evidence. Furthermore, few of those interviewed expressed any knowledge of SCQF documents and guidelines and hardly anyone mentioned the bodies associated with the SCQF (for example The Partnership, The Forum).

It is also questionable to what extent the findings here regarding SCQF would be mirrored had the research also pursued similar research objectives with respect to other QAA benchmarking documentation (cf Newton 2000). Cynically, one could further argue that the 
SCQF simply lacks any real substance or purchase in higher education academic practice and that its adoption is merely a process of engaging in symbolic activity rather than establishing a groundswell of support and appetite for its deeper integration and use within the academic practices of higher education (cf Anderson 2006; Cheng 2011). However, if this is the case, it is extremely difficult to see how decisions about the levels of SCQF qualifications are made by those professionals best placed to do so, as the user guide claims.

The SCQF appears not to be for most academics and mirrors similar claims made by Houston (2010) about the impact of quality assurance mechanisms in higher education more widely. It could be argued that what is reported here echoes the point made by Vidovich (2002) that mechanisms associated with quality are shifting from management devices to marketing devices. Broadly, strategic management's view is that the framework is the basis for legitimising what the institution already does, which can be then used as a platform for marketing. In other words, it is not something used to instrumentally influence current academic practices that shape products such as course/programme designs and admissions processes and procedures. Inevitably, in order to hold weight as a marketing tool for its product, it has to claim resonance and power over this product. This supports the strategic management view that lecturers had no need to know about the SCQF as its aims were more political and economic; aims which could be construed from SCQF documentation but not ones which are explicitly stated. The Framework is arguably not therefore viewed by most academic practitioners as something to improve academic quality. It is there to reflect and reinforce the quality that is already being delivered.

It is understandable from a pedagogical perspective that mobility around Europe was highlighted by the interviewees, given its currency in present European policy and 
educational debate (cf Keeling 2006). Such mobility is connected to the wider debates on social mobility across Europe; however, it is possible that such mobility impacts upon the import and export of education. This latter point echoes strategic management views concerning the commercialisation of higher education. When mobility deals with postgraduate students and those from outside the European Union, this import and export assumes monetary value. Viewing the SCQF as a means to export Scottish education/qualifications is certainly an interesting hypothesis for further research.

While the SCQF should facilitate internal (Scottish) mobility, a number of practical tensions and power struggles emerged. In particular, the movement from FE to HE had highlighted the issue of power over decisions of eligibility for entry (cf Morgan-Klein 2003). A related tension was with regard to the idea of distinction versus homogeneity of courses and programmes and issues of equivalence. Whilst it was considered that different courses were comparable, there was a tension around the skill set learners attained being different, thus making it hard for them to smoothly transfer into another institution. Indeed this hints at the notion that there is a blurring of the boundaries between the content and contribution of FE and HE. It is debatable whether this is an unintended outcome of the SCQF. On a related note, there was also a concern that the standardisation resulting from increased homogeneity of courses via SCQF levels could lead to an emphasis on the lowest common denominator and a subsequent 'dumbing down' of higher education. Rather than the SCQF facilitating a smooth transition between levels of study (SCQF 2009), it has created tensions over entry and exit points and a concern over the quality of higher education (cf Field 2004).

\section{Conclusion}


Perhaps naively, the research team assumed that the purpose of the SCQF was to impact upon the content, detail and quality of academic practice. Simplistically put, our answer to the question 'has the SCQF impacted practice in higher education?' would be yes and no. Yes, there is undoubtedly evidence within this case study to suggest that the SCQF is a framework used within higher education. Yes, without doubt most lecturers understand that their courses and programmes of study use the SCQF levels as a way to describe their courses and programmes of study on QAA and internal forms and documents. Symbolism apart, the claim that the SCQF is well established (e.g. SCQF 2001; 2009; Raffe 2003) is problematic as it has failed to substantively penetrate, impact upon and change academic practice. Essentially, while the SCQF levels in the documentation of higher education are well established they stand in stark contrast to the levels of impact on higher education practice. However, we are left with a question here, is this a problem?

The most convincing argument for the existence of the SCQF is, according to this study, that it is either a necessity of European policy, part of an ongoing drive for harmonisation across Europe or, that the SCQF facilitates the commodification and global marketing of Scottish education products. In this sense, the impact of the SCQF and the role it plays in practice is split according to the divide between internal and external stakeholders. This research supports a view that the SCQF is not, has not and possibly should not substantively impact upon academic pedagogy and practice for internal stakeholders. Further research should focus on the SCQF's impact upon other institutions within Scotland and external stakeholders. Furthermore, research should potentially be informed by marketing and economic paradigms. For example future research could be targeted at attempting to measure the success of the SCQF in terms of how it is increasing the numbers of students (i.e. capital) 
coming to study in Scotland. Also, if, as has been often noted (cf Raffe 2003; Young 2008), the SCQF is 'successful', two key questions arise: Who is it successful for? How is its success to be measured? This issue can be framed in another, Foucauldian way, and defined through its opposite: if an NQF is said to have 'failed', how is this defined? Who has it failed for? How is this to be measured? The SCQF has managed to avoid the pitfalls of a supposed failing framework (such as the South African Framework (cf Allais 2007a)) by having little or no impact on academic pedagogy and practice. Similarly, it has been successful in avoiding any ‘transformation’ by simply mapping onto existing practices. This raises the question of the actual raison d'être of the SCQF. Is its inclusion as a pivotal touchstone for QAA necessary to ostensibly legitimise quality for external stakeholders?

\section{References}

ALLAIS, S. (2007a) Why the South African NQF Failed: lessons for countries wanting to introduce national qualifications frameworks. European Journal of Education, 42, pp. 523-547

ALLAIS, S (2007b) Education service delivery: the disastrous case of outcomes-based qualifications frameworks. Progress in Development Studies 7, pp. 65-78

ALLAIS, S (2009) Smoke and Mirrors. What's really informing the growth of national qualifications frameworks internationally? Paper presented at the $10^{\text {th }}$ UKFIET conference Oxford University, 14 - 17 September 2009

ALLAIS, S and YOUNG, M (2009) Conceptualizing the role of qualifications in education reform In STEPHANIE ALLAIS, DAVID RAFFE, MICHAEL YOUNG, \& International Labour Office. Researching NQFs: Some conceptual issues (Geneva: ILO) pp. $5-22$ 
ANDERSON, G. (2006) Assuring Quality/Resisting Quality Assurance: Academics’ responses to 'quality' in some Australian universities. Quality in Higher Education, 12, pp 161-173

BLACKMUR, D. (2004) A critique of the concept of a national qualifications framework. Quality in Higher Education 10, pp. 267-284

BLACKMUR, D. (2010) Does the Emperor have the right or any) Clothes? The public regulation of higher education qualities over the last two Decades. Quality in Higher Education, 16, pp. 67-69

BOLOGNA (2005) BOLOGNA WORKING GROUP ON QUALIFICATIONS FRAMEWORKS. A framework for qualifications of the European higher education area. Copenhagen. (Ministry of Science, Technology and Innovation)

BOLOGNA (2007) Bologna Process Stocktaking London 2007. Department for Education and Skills. Available at:

http://www.ond.vlaanderen.be/hogeronderwijs/bologna/documents/WGR2007/Stocktaking _report2007.pdf

BRESNEN, M. (1988) Insights On Site: Research into construction project organisations, in: ALAN BRYMAN (ed.) Doing Research in Organisations (London, Routledge)

BREW, A. (2010) Transforming academic practice through scholarship, International Journal for Academic Development, 15, pp. 105-116

CHENG, M. (2011) The perceived impact of quality audit on the work of academics. Higher Education Research \& Development, 30, pp. 179-191

DIXON, K. (2009) Curricular Accounting the Canterbury way. University of Canterbury, Christchurch, New Zealand: 3rd New Zealand Conference on Management Accounting, 19-20 Nov 2009. 
EC (EUROPEAN COMMISSION) (2005) Towards A European Qualifications Framework for Lifelong Learning, SEC (2005) 957 (Brussels: European Commission)

EISENHARDT, K. M. (1989) Building theories from case study research. Academy of Management Review, 14, pp. 532-550.

EUA (2005) Trends IV: European Universities Implementing Bologna. Available at: http://www.bologna-bergen2005.no/Docs/02-EUA/050425_EUA_TrendsIV.pdf

EUA (2010) Trends 2010: A decade of change in European Higher Education. Available at: http://www.eua.be/eua-work-and-policy-area/building-the-european-higher-educationarea/trends-in-european-higher-education/trends-vi.aspx

FERNIE, S., \& PILCHER, N. (2009). National Qualification Frameworks: Developing Research Perspectives. Quality in Higher Education, 15, pp. 221-232.

FIELD, J. (2004) Articulation and credit transfer in Scotland: taking the academic highroad or a sideways step in a ghetto? Journal of Access Policy and Practice, 1, pp. 85-99

FLYVBJERG, B (2011) Case Study, in: NORMAN K DENZIN \& YVONNA S LINCOLN (Eds) The Sage handbook of qualitative research. Thousand Oaks: Sage, pp. 301-16

FOUCAULT, M (1973) Truth and Juridical Forms, In JAMES D. FAUBION (Ed) (2000) Essential Works of Foucault. Volume 3. Power. (New York: the New Press)

GALLACHER, J., TOMAN, N., CALDWELL, J., EDWARDS, R. \& RAFFE, D. (2005). Evaluation of the impact of the Scottish Credit and Qualifications Framework (SCQF), (Scottish Office Central Research Unit)

GREEN, A. (2002) The many faces of lifelong learning: recent education policy trends in Europe Journal of Education Policy, 17, pp. 611-626 
GUNNING, D. (1999) A National Qualifications framework - the Scottish Experience Namibian Qualifications’ Framework Conference, Windhoek, Namibia.

HETAC (2007) EXTERNAL REVIEW OF HETAC. Avaliable at: http://www.hetac.ie/publications_review.htm

HOUSTON, D. (2010). Achievements and Consequences of Two Decades of Quality Assurance in Higher Education: A Personal View From the Edge. Quality in Higher Education, 16, pp. 177-180

IBE (2010) NQF AND YOU. Available at: http://www.kwalifikacje.org.pl/eng/frameworkfor-you

JIA, W. (2001) The Remaking of the Chinese Character and Identity in the $21^{\text {st }}$ Century. The Chinese Face Practices. (Westport: Ablex Publishing)

KARSETH, B., \& SOLBREKKE, T., D. (2010). Qualifications Frameworks: the avenue towards the convergence of European higher education? European Journal of Education, 45, pp. 563-576

KEELING, R. (2006), The Bologna Process and the Lisbon Research Agenda: the European Commission's expanding role in higher education discourse. European Journal of Education, 41, pp. 203-223

MENMUIR, J (2003) (2 ${ }^{\text {nd }}$ Ed.) SCOTCAT and scqf arrangement. In Bryce, T.G.K and Humes, W.M (Eds.) Scottish Education: post devolution. Edinburgh, Edinburgh University Press, pp 974 - 981

MORGAN-KLEIN, B. (2003), Scottish Higher Education and the FE-HE Nexus. Higher Education Quarterly, 57, pp. 338-354

MULLEN, F. (2007) Lifelong Learning: Higher Education. SPICe briefing 07/45. Available at: http://www.scottish.parliament.uk/business/research/briefings07/SB07-45.pdf 
MULLEN, F. (2010) Barriers to widening access to higher education, Scottish Parliament Information Centre (SPICe) Briefing 10/07 Available at: http://www.scottishparliament.eu/business/research/briefings-10/SB10-07.pdf [accessed at 30 March 2011] NATIONAL COMMITTEE OF INQUIRY INTO HIGHER EDUCATION, \& DEARING, R. (1997). Higher education in the learning society. Summary report. London, NCIHE.

NEWTON, J. (2000) Feeding the Beast or Improving Quality?: Academics' perceptions of quality assurance and quality monitoring. Quality in Higher Education, 6, pp. 153-163

OECD (ORGANISATION FOR ECONOMIC COOPERATION AND DEVELOPMENT) (2007) Qualifications Systems: Bridges to Lifelong Learning (Paris: OECD)

POLAND, B, D (2001) Transcription Quality. In JABER F GUBRIUM \& JAMES A HOLSTEIN (2001). Handbook of interview research (Thousand Oaks: Sage)

PRIOR, L. (2003) Using documents in social research (London: Sage)

QAA (2011a) The work of QAA Scotland. Enhancing Quality in Scottish Higher Education. Avaliable at http://www.qaa.ac.uk/Publications/InformationAndGuidance/Documents/IntroToQA AScotland.pdf

QAA (2011b) Changes to the academic infrastructure: final report. Available at: http://www.qaa.ac.uk/Documents/qualitycode.pdf

RAFFE, D. (2003) 'Simplicity Itself': The creation of the Scottish Credit and Qualifications Framework. Journal of Education and Work, 16, pp. 239-257

RAFFE, D. (2007) Making Haste Slowly: the evolution of a unified qualifications framework in Scotland. European Journal of Education 42, pp. 485 - 502

RAFFE, D. (2008) The Action Plan, Scotland and the making of the modern educational world: the first quarter century, keynote address at the Annual Conference of the Scottish Educational Research Association, Perth, November 2008 
RAFFE, D. (2009b) National Qualifications Frameworks in Ireland and Scotland:

A Comparative Analysis, European Conference on Educational Research, Vienna, 28-30

September 2009

SCQF (2001) An Introduction to the Scottish Credit and Qualifications Framework (Scottish Executive)

SCQF (2009) SCQF Handbook: User guide. (The SCQF Partnership)

SCQF (2010a) Frontline we help you do things better. SC9702-00 - (SCQF Partnership Final Report 16th July)

SCQF (2010b) Nomenclature explained - a guide to naming qualifications and learning programmes for the SCQF (SCQF Partnership resources) available at http://www.scqf.org.uk/Resources/

SCQF (2011) Credit Rating and Benchmarking: What's the difference? The SCQF: Glasgow. Available at:

http://www.scqf.org.uk/content/files/Whats_the_difference_leaflet_for_website_FINAL__Jan_2011.pdf [Accessed 20 December 2011]

SFC (SCOTTISH FUNDING COUNCIL)(2005) Learning for All: The Report of the SFEFC/SHEFC Widening Participation Review Group. Available at: http://archive.sfc.ac.uk/publications/pubs_other_sfcarchive/learning_for_all_publication_s eptember_2005.pdf [Accessed 28 January 2010].

SIKES, P (2010) The ethics of writing life histories and narratives in educational research. In ANNE-MARIE BATHMAKER \& PATRICIA HARNETT (Eds) Exploring learning, identity, and power through life history and narrative research (London: Routledge) pp 11 $-24$

Stoeker, R. (1991) Evaluating and rethinking the case study The Sociological Review, 39, pp. 88-112 
UK EQF (2010) UK EQF Launch Conference . Referencing the UK frameworks to the European Qualification Framework Report of the Edinburgh Conference, 26-27 April, 2010. Available at: http://live.theeab.org.uk/files/2010-uk-eqf-launch-conferencereport.pdf?Itemid $=143$

VIDOVICH, L. (2002) Quality assurance in Australian higher education: Globalisation and `steering at a distance', Higher Education, 43, pp. 391-408

YOUNG, M (2003) National Qualifications Frameworks as a Global Phenomenon: a comparative perspective. Journal of Education and Work, 16, pp. 223 - 237

YOUNG, M. (2008). Towards a European qualifications framework: some cautionary observations. Journal of European Industrial Training, 32, pp. 128-137 